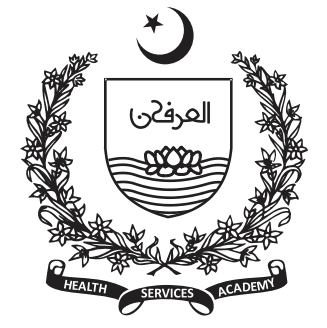

1 Post Graduate Trainee, Ghurki Hospital

${ }^{2}$ Assistant Professor, Dept. of Community Medicine, FMH College of Medicine and Dentistry, Shadman, Lahore, Pakistan

Corresponding Author: Khadeej Choudhry Ilyas Email:

khadeej.ch@gmail.com

\section{Opinion and Usage Regarding Complementary and Alternative Therapies among Patients at a Tertiary Care Hospital in Lahore, Pakistan}

\author{
Khadeej Choudhry Ilyas ${ }^{1}$, Naureen Omar ${ }^{2}$
}

\section{Abstract}

Background: Complementary and alternative medicine (CAM) therapies are widely used among the population in Pakistan either separately or in conjunction with convention medical therapies. CAM therapies are used for varying reasons and result in complications as conventional treatment is often delayed resulting in increased morbidity and mortality. Objective of the study was to assess the opinions and usage regarding CAM therapies among patients in a tertiary care setup.

Methods: Cross sectional study was conducted at Fatima Memorial Hospital, Lahore from April 2018 to June 2018. Sample size was calculated to be 186 which were equally divided between patients in OPD, ER and IPD. A structured questionnaire was administered. SPSS 20 was used for analysis.

Results: In this study $112(60.2 \%)$ patients had used CAM for an illness whereas $74(39.8 \%)$ had never used CAM therapy. Most of the patients $165(88.7 \%)$ were able to differentiate between CAM and conventional therapies. Most frequent source of knowledge cited was family and friends $139(74.7 \%)$, previous users of CAM $83(44.6 \%)$ and media/internet $69(37.1 \%)$. Spiritual Healers (Pirs) were the most used modality of CAM at $64(34.4 \%)$ followed by hakeem and homeopathy. Most common reasons for using CAM were advice from family and friends, personal will and religious/spiritual reasons.

Conclusion: Use of CAM therapies is widely prevalent in our study with more than half the respondents having used a modality of CAM. Users of CAM were found to be generally satisfied with the treatment.

Keywords: Complementary therapies, health knowledge, attitudes, practice, Pakistan. 


\section{Introduction}

C

omplementary and Alternative medicine (CAM) has been widely practiced around the globe for centuries. Despite the rise of evidence based modern medicine over the past century the use of CAM therapies is rising in the developed world, whereas it was already high in the developing world (1). CAM is defined as a group of diverse medical practices which are not currently considered an integral part of conventional allopathic medical practice. They lack biomedical evidence of their efficacy. Therapies are termed as Complementary when used in addition to conventional treatments and as Alternative when used instead of conventional treatment (2).

Pakistan traditionally and culturally has a high trend of CAM with prevalence of $53.5 \%$ (3). In other developing countries it also remains high with $57.2 \%$ in India (4) and $82.1 \%$ in Nigeria (5). Even in developed countries there is significant usage of CAM with prevalence rates in USA standing at $34.2 \%$ [6], $36 \%$ in Scandinavian countries namely Norway, Denmark and Sweden (7).

The significant use of CAM therapies in the developing countries is often attributed to three factors i.e. poverty, illiteracy and lack of access to healthcare facilities (8). The recent surge in the usage of CAM therapies in the developed world over the past decade, however, indicates that these factors alone do not explain the reason why an individual seeks CAM therapy. Therefore given the different cultural, religious and socioeconomic makeup of the different countries it indicates that other factors play a considerable role in an individual's decision to use CAM therapy. In the developed countries this rise has been attributed to dissatisfaction with conventional healthcare as well as easier access to unregulated alternative medicines on the internet that promise easy and miraculous cures especially for diseases where modern treatments fall short such as chronic pain and other debilitating diseases. Other reasons for usage of CAM remain common to both developed and developing countries such as expensive cost of treatments, concerns about side effects, poor prognosis of certain diseases such as advanced cancer and dismissive attitude of the physicians (9).

In developing countries like Pakistan most common CAM therapies used are herbal, spiritual and homeopathy $(9,10)$. Multiple studies show that the most common reason for using CAM in Pakistan is insistence of family and close friends $(10,11)$, with other frequent reasons cited being financial constraints and not benefitting from conventional medicine $(10,11)$.

This study was based on a questionnaire administered to patients seeking treatment at a private tertiary care hospital in Lahore. The study focused on identifying the reasons as to why people seek CAM therapies and help policymakers in taking measures to address them, as unlike conventional treatments which undergo vigorous testing and trials before becoming standard practice, CAM therapies have little or no scientific evidence regarding their efficacy. The use of CAM can lead to a worse prognosis of a disease as well as increased morbidity and mortality especially in diseases where earlier interventions result in a much better prognosis (12). Tertiary care hospitals are burdened with these complicated and mismanaged cases which may be avoided if we are able to reduce the use of CAM. Thus we targeted to study knowledge, attitude and practices regarding CAM among patients in a tertiary care setup in Pakistan.

\section{Methodology}

This cross-sectional study was conducted at Fatima Memorial Hospital, Lahore from April 2018 to June 2018. Approval was obtained from the Institutional Review Board of Fatima Memorial Hospital.

The sample size was estimated using Sample Size Determination in Health Studies Version 2.0.21, World Health Organization. At 95\% confidence interval considering $\mathrm{p}$ - value $<0.005$ the calculated sample amounts to 186 . The calculated sample was divided into three equal parts and equal numbers of patients were enrolled from the inpatient, outpatient and emergency departments respectively. Inclusion criteria for this study were patients above 18 years of age, consenting and those admitted in inpatient at the hospital or presenting to the outpatient or emergency services regardless of the specialty department they were presenting to. Patients below 18 years of age, non-consenting and those requiring urgent care in emergency or admitted in intensive care/ high dependency units were excluded. Non-probability convenient sampling was used and data was collected with the help of a structured questionnaire after 
obtaining written consent. Interviews were conducted in person by the principal investigator.

SPSS version 20 was used for data entry and analysis. Percentage and frequency tables were prepared for qualitative variables. Chi-square test was applied for evaluating the significance of association between qualitative variables with a value of $\mathrm{P}<0.05$ being taken as significant.

\section{Results}

The study involved a total of 186 patients. The total sample was divided into three equal parts with $62(33.3 \%)$ patients, each being selected from the inpatient, outpatient and emergency departments respectively of Fatima Memorial Hospital, Lahore, Pakistan.

The distribution of gender was almost equal with $96(51.6 \%)$ being females and $90(48.4 \%)$ being males. Age of the respondents ranged from 18 to 85 years with a mean age of $37.3 \pm 14.5$. As far as the educational status was concerned $37(19.9 \%)$ were illiterate, $43(23.1 \%)$ belonged to primary/secondary, $34(18.3 \%)$ matriculate, $29(15.6 \%)$ intermediate, $30(16.1 \%)$ had completed a bachelor programme and $13(7 \%)$ had achieved a master degree. In a total of 186 $55(29.6 \%)$ were single, $117(62.9 \%)$ married, 9(4.8\%) divorced and 5(2.7\%) were widowed. Mean monthly household income among the respondents was $38,225 \pm 23,730$. Participants hailing from rural area were $32(17.2 \%)$ compared to $39(21 \%)$ from households located in peri-urban areas and 115(61.8\%) lived in an urban area.

As shown in Figure 1 family and friends were the most common source of knowledge for CAM therapies with the second most common source of information being people who had previously used CAM therapies. Media/Internet was important with one-third of respondents attributing it as their source. Communal places and newspapers/books/pamphlets were the other sources from which people derived their knowledge of various CAM therapies.

In our study $165(88.7 \%)$ patients were able to differentiate between conventional, complementary and alternative therapies, whereas $21(11.3 \%)$ were unable to differentiate between them. The total number of patients who had used CAM therapy for an illness was $112(60.2 \%)$, whereas those who had never used CAM were 74(39.8\%).
Familiarity with different CAM modalities and whether they were perceived as beneficial is shown in Table 1.

Most frequently CAM modality used was Spiritual healers (Pirs) with more than half the users having sought them out for treating their illness. Homeopathy was the second most common used modality. Other modalities included Hakeems, Manipulation and lastly Herbal/Ayurveda as shown in Table 2.

More than half of the users reported having benefited from CAM, with $65(58 \%)$ reporting having benefited whereas $47(42 \%)$ reported worsening or no benefit to their illness.

Advice from family and friends was the most potent variable with almost three quarter citing it as their reason for seeking treatment with CAM. Personal will and religious beliefs were other significant variables. Other reasons stated for using CAM were poor prognosis offered by conventional treatment, high cost of conventional treatment, lack of access to a healthcare facility and concerns about side effects of allopathic medicines as shown in Table 2.

\section{Source of Knowledge of CAM Therapies}

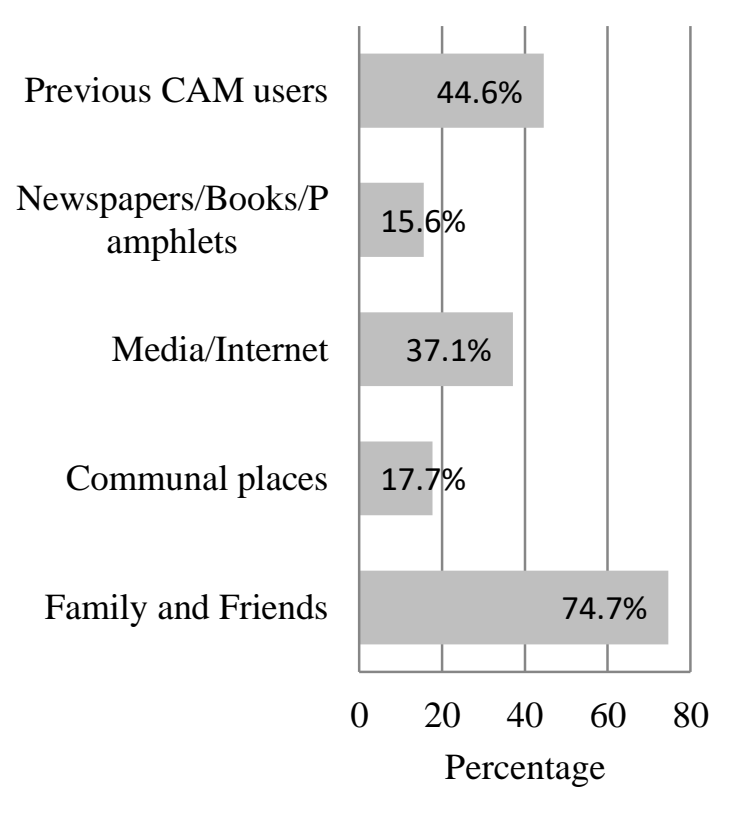

Figure 1: Source of Knowledge Regarding CAM Therapies 
Table 1: Knowledge regarding CAM Therapies among patients of tertiary care setup

\begin{tabular}{|l|c|c|}
\hline & $\begin{array}{c}\text { Frequency } \\
\text { (n) }\end{array}$ & $\begin{array}{c}\text { Percentage } \\
\text { (\%) }\end{array}$ \\
\hline Familiarity regarding CAM & 112 & 60.2 \\
Therapy & 160 & 86 \\
Yoga & 160 & 86 \\
Homeopathy & 161 & 86.6 \\
Manipulation & 177 & 95.2 \\
Ayurveda/Hakeem & & \\
Spiritual Healer & & \\
& 106 & 57 \\
\hline Beneficial Opinion regarding & 95 & 51.1 \\
CAM Therapy & 86 & 46.2 \\
Yoga & 98 & 52.7 \\
Homeopathy & 113 & 60.8 \\
Manipulation & & \\
Ayurveda/Hakeem & & \\
Spiritual Healer & 58 & 36.6 \\
\hline Amount of Information & 52 & 28 \\
regarding CAM Therapy & 38 & 20.4 \\
Sufficient & & \\
Slightly Sufficient & & \\
Insufficient & & \\
\hline Likelihood to recommend CAM & & \\
therapies to relatives and/or & & \\
friends & & \\
Yes & & \\
No & & \\
\hline
\end{tabular}

Table 2: Usage of CAM Therapies

\begin{tabular}{|l|c|c|}
\hline & $\begin{array}{c}\text { Frequency } \\
\text { (n) }\end{array}$ & $\begin{array}{c}\text { Percentage } \\
\text { (\%) }\end{array}$ \\
\hline Used CAM for their Illness & 112 & 60.2 \\
Yes & 74 & 39.8 \\
No & & \\
\hline Effect of CAM Therapy on & 65 & 58 \\
Illness & 47 & 42 \\
Benefited & & \\
Worsened & 31 & 27.7 \\
\hline CAM: type being used & 8 & 7.1 \\
Homeopathy & 50 & 44.6 \\
Herbal/Ayurveda & 18 & 16.1 \\
Hakeem & 64 & 57.1 \\
Manipulation & & \\
Spiritual Healer & 83 & 74.1 \\
\hline Reason for using CAM & 28 & 25 \\
therapy & 38 & 33.9 \\
Advice from family and/or & & \\
friends & & \\
\hline
\end{tabular}

\begin{tabular}{|l|c|c|}
\hline Religious and/or Spiritual & 19 & 17 \\
Reasons & 16 & 14.3 \\
Personal Will & 24 & 21.4 \\
Cost of treatment by & 6 & 5.4 \\
medical practitioner & & \\
Lack of access to healthcare & & \\
facility & & \\
Poor prognosis offered by & & \\
conventional treatment & & \\
Concerns about side effects & & \\
of allopathic medicine & & \\
\hline
\end{tabular}

Table 3: Cross-tables with p-values

\begin{tabular}{|c|c|c|c|}
\hline Variables & \multicolumn{2}{|c|}{$\begin{array}{c}\text { Opinion on illness after } \\
\text { using CAM }\end{array}$} & $\begin{array}{c}\text { p- } \\
\text { value }\end{array}$ \\
\hline $\begin{array}{l}\text { Likely to recommend } \\
\text { CAM therapies } \\
\text { Yes } \\
\text { No }\end{array}$ & $\begin{array}{c}\text { Benefited } \\
57 \\
8\end{array}$ & $\begin{array}{c}\text { Worsened } \\
25 \\
22\end{array}$ & 0.0001 \\
\hline & \multicolumn{2}{|c|}{$\begin{array}{l}\text { Used CAM therapy for } \\
\text { an Illness }\end{array}$} & \\
\hline $\begin{array}{l}\text { Gender } \\
\text { Male } \\
\text { Female }\end{array}$ & $\begin{array}{c}\text { Yes } \\
44 \\
68 \\
\end{array}$ & $\begin{array}{c}\text { No } \\
46 \\
28 \\
\end{array}$ & 0.002 \\
\hline $\begin{array}{l}\text { Residence } \\
\text { Rural } \\
\text { Peri-urban } \\
\text { Urban } \\
\end{array}$ & $\begin{array}{l}\text { Yes } \\
24 \\
18 \\
70\end{array}$ & $\begin{array}{c}\mathrm{No} \\
8 \\
21 \\
45\end{array}$ & 0.046 \\
\hline $\begin{array}{l}\text { Age } \\
18-25 \\
26-40 \\
41-60 \\
60+ \\
\end{array}$ & $\begin{array}{c}\text { Yes } \\
24 \\
47 \\
34 \\
7 \\
\end{array}$ & $\begin{array}{c}\text { No } \\
26 \\
20 \\
19 \\
9 \\
\end{array}$ & 0.045 \\
\hline $\begin{array}{l}\text { Education } \\
\text { Illiterate } \\
\text { Primary/Secondary } \\
\text { Matriculation } \\
\text { Intermediate } \\
\text { Bachelors } \\
\text { Masters and Above }\end{array}$ & $\begin{array}{c}\text { Yes } \\
18 \\
14 \\
14 \\
17 \\
19 \\
1\end{array}$ & $\begin{array}{l}\text { No } \\
19 \\
29 \\
20 \\
12 \\
11 \\
12\end{array}$ & 0.005 \\
\hline
\end{tabular}

The annual expenditure on CAM Therapies in the United States alone stands approximately 30 Billion dollars annually (13), which is more than the annual gross domestic product of countries such as Iceland, Nepal and Zimbabwe (14).

The current study witnessed more than half patients $60.2 \%$ were using CAM, which is higher than the figures stated in other studies done in Pakistan of $51.7 \%$ (3) but closer to the figures stated in an Indian study (4). This difference can be attributed to the fact 
that previous studies have tended to mostly look at a single disease whereas in our study patients suffering from a wide spectrum of illnesses both acute and chronic were included. It is also pertinent to mention that the respondents included were those presenting in general outpatient department and general ward where patients are treated at subsidised rates, hence serving mostly to the lower socioeconomic class as can be observed by the mean income among the participants of this study.

A 2016 study conducted at SIUT, Pakistan by Lail et al. (11) showed that the most common CAM modalities used were spiritual healing, homeopathy and hakeem/herbal medications, our findings were similar with spiritual healing being the most frequent followed by hakeem/herbal and homeopathy respectively. The same study also found that among its participants the use of CAM therapies was highest among those who were illiterate or had attained primary education concurrent with our study which showed significant use among all educational groups, but it was found to be the highest among the illiterate and those with a primary education $(\mathrm{p}<0.05)$. These findings can be attributed to the cultural and religious beliefs accentuated by illiteracy within our community. A study by Sharma et al. (15) in North India found no significant association between education and CAM usage. This could be due to cultural/ religious differences between the two countries, due to which attainment of higher education in Pakistan decreases the likelihood of using CAM therapies but in India higher education does not decrease the likelihood of using CAM therapy.

In the developed countries the use of CAM is seen mostly in people with postmodern views about medicine and being more compatible with their values, spiritual/religious philosophy, or beliefs regarding the nature and meaning of health and illness (16). In our society the usage of CAM is primarily driven by advice of family and friends when a patient falls ill. Family and friends were the source of information regarding CAM for $74.7 \%$ of patients who were interviewed followed by $44.6 \%$ patients who got their information from patients who had been previously treated with CAM therapy. This is in line with other researches that have shown that the main reasons for consulting a CAM healer are family pressure and strong opinions of the community, affordable fee and proximity (17).
Our study witnessed a majority of patients perceiving to have benefited from the usage of CAM therapy for their illness. This is pertinent as most seek professional healthcare after CAM fails to improve their health. High satisfaction was reported by CAM users in our study which was similar to a study conducted by Hussain et al. (18) in public hospitals of Lahore, which also showed high satisfaction among the majority of users who had used CAM therapies in the past. These findings are significant as they highlight the fact that patients believing to have benefited from using CAM therapies are more likely to recommend CAM therapies to others $(\mathrm{p}<0.001)$ as shown in Table 3.

In this study a greater tendency for usage of CAM was observed among the female patients as compared to the males $(p<0.01)$, whereas a study conducted by Ayaz et al. (19) in Rawalpindi found no significant association between gender and usage of CAM therapies. The Rawalpindi (19) study also found significant association of age with CAM usage which is found in this study as well $(\mathrm{p}<0.05)$. It should be noted that in the Rawalpindi study the mean age of the participants was $62 \pm 10$ years whereas in our study the mean age was $37.3 \pm 14.5$. This indicates that the older age group is more likely to use CAM therapies for their illness. This is significant because this age group is more at risk of developing chronic diseases which lead to increased morbidity and mortality if proper diagnosis and treatment is delayed.

In this study residence, whether rural or urban, of the patients was found to have significant association with using CAM therapies $(\mathrm{p}<0.05)$, which is in line with the findings of the Rawalpindi study [19] and a study done by Roy et al. (20) New Delhi, India. This association may be explained due to higher levels of poverty, illiteracy and poorer medical infrastructure in rural areas.

Usage of CAM therapies was seen across the income spectrum and no significant association with monthly household income was found ( $p>0.05)$. These findings were in line with those of a previous single centre study conducted in Rawalpindi (19).

It should be noted that this research was conducted at a private tertiary care hospital located in urban Lahore so its results cannot be generalised to the whole population. Similar studies should be conducted at multiple centres across the country for a more representative sample from which more generalizable results could be obtained. 


\section{Conclusion}

Use of CAM therapies is widely prevalent in our study with more than half of the respondents using a modality of CAM therapy. More than half of the respondents who had used CAM therapy were satisfied with the treatments. People derive their knowledge of CAM from a wide variety of sources and use CAM due to different reasons, but family and friends were cited as the most common for both, source of knowledge of CAM therapies and as a reason for using CAM therapy.

\section{Limitations:}

This self-funded research was limited to only one tertiary care hospital. Secondly, this research was conducted in an urban setting so its results cannot be necessarily applied to rural settings.

\section{References}

1. Stapleton $P$, Chatwin H, Boucher E, Crebbin S, Scott $S$, Smith D, Purkis G. Use of complementary therapies by registered psychologists: An international study. Prof Psychol Res Pr. 2015;46(3):190

2. National Cancer Institute. 2020. Complementary And Alternative Medicine (CAM). [online] Available at: <https://www.cancer.gov/aboutcancer/treatment/cam> [Accessed 1 September 2020].

3. Jawed K, Nisar N, Hussain M, Nawab F. A study based on use of Complementary and Alternative Medicine among Diabetic Patients in Karachi, Pakistan. J Dow Univ Health Sci. 2019;13(1).

4. Ray J, Chakrabarty D, Paul R, Som K. Prevalence of the use of complementary and alternative medicine in an eastern Indian population with emphasis on tribal/ethnic minority groups. J Taibah Univ Med Sci. 2018;13(4):384-9.

5. Onyiapat JL, Okafor C, Okoronkwo I, Anarado A, Chukwukelu E, Nwaneri A, Okpala P. Complementary and alternative medicine use: Results from a descriptive study of pregnant women in Udi local Government area of Enugu state, Nigeria. BMC Complement Altern Med. 2017;17(1):189.

6. Murthy V, Sibbritt DW, Adams J. An integrative review of complementary and alternative medicine use for back pain: a focus on prevalence, reasons for use, influential factors, self-perceived effectiveness, and communication. Spine J. 2015;15(8):1870-83.

7. Nilsson J, Kallman M, Östlund U, Holgersson G, Bergqvist M, Bergström S. The use of complementary and alternative medicine in Scandinavia. Anticancer Res. 2016;36(7):3243-51.
8. Shewamene Z, Dune T, Smith CA. The use of traditional medicine in maternity care among African women in Africa and the diaspora: a systematic review. BMC Complement Altern Med. 2017;17(1):382.

9. Johnson PJ, Kozhimannil KB, Jou J, Ghildayal N, Rockwood TH. Complementary and alternative medicine use among women of reproductive age in the United States. Women's Health Issues. 2016;26(1):40-7.

10. Junaid R, Abaas M, Fatima B, Anis I, Hussain M. Attitude and practice of patients and doctors towards complementary and alternative medicine. J Pak Med Assoc. 2012;62(8):865-8.

11. Lail G, Luck N, Tasneem AA, Rai A, Laeeq SM, Majid Z. The usage of complementary and alternative medicine in gastrointestinal patients visiting the outpatients' department of a large tertiary care centre-views from Pakistan._Pan Afr Med J. 2016;24.

12. Johnson SB, Park HS, Gross CP, Yu JB. Use of alternative medicine for cancer and its impact on survival. JNCI: J Natl Cancer Inst. 2017;110(1):121-4.

13. Purohit MP, Zafonte RD, Sherman LM, Davis RB, Giwerc MY, Shenton ME, Yeh GY. Neuropsychiatric symptoms and expenditure on complementary and alternative medicine. J. Clin. Psychiatry. 2015;76(7):870.

14. Imf.org. (2019). World Economic Outlook Database April 2019. [online] Available at: https://www.imf.org/external/pubs/ft/weo/2019/01 /weodata/index.aspx [Accessed 10 May 2019].

15. Sharma E, Dubey AK, Malhotra S, Manocha S, Handu S. Use of complementary and alternative medicines in Indian elderly patients. Natl J Physiol Pharm Pharmacol. 2017;7(9):929.16:

16. Isaac KS, Hay JL, Lubetkin EI. Incorporating spirituality in primary care. J Relig Health. 2016;55(3):1065-77.

17. Mustafa G, Bashir N, Aslam M. Parental beliefs and practice of spiritual methods for their sick children at a tertiary care hospital of Pakistan-a cross sectional questionnaire study. BMC Complement Altern Med. 2015;16(1):14.

18. Hussain A, Ayesha, Mufti RK, Shahid M, Hassan MN, Sultan T, Zahid MN, Ali I, Iqbal H. Determinants of patients preferring Complementary and Alternative medicine attending public hospitals in Lahore, Pakistan. J Pak Med Assoc. 2018;68(6):914-8.

19. Ayaz SB, Rathore FA, Ahmad K, Matee S. The use of complementary health approaches among patients with knee osteoarthritis in Pakistan: A hospital based survey. Egypt. Rheumatol. 2016;38(2):111-6.

20. Roy V, Gupta M, Ghosh RK. Perception, attitude and usage of complementary and alternative medicine among doctors and patients in a tertiary care hospital in India. Indian J Pharmacol. 2015;47(2):137. 